\title{
A ELETRENCEFALOGRAFIA NO DIAGNÓSTICO E PROGNÓSTICO DOS ABSCESSOS CEREBRAIS
}

\author{
Paulo Pinto Pupo * \\ Aloysio Mattos Pimenta ** \\ ORESTES BARINI ***
}

A eletrencefalografia, sendo um método de exame funcional do encéfalo de fácil execução, inócuo para o paciente, possivel de ser repetido quantas vêzes se faça necessário, oferece perspectivas muito satisfatórias para a semiologia em pacientes em precário estado geral ou com grave comprometimento encefálico. Neste grupo se situam, não raro, os casos de abscesso cerebral. É justamente para êsses casos que Pennybacker ${ }^{\$}$ assinala ser a eletrencefalografia indicada, pois oferece os resultados mais úteis e imediatos para o diagnóstico topográfico da afecção e que permitem suspeitar o diagnóstico etiológico. A justificativa do uso da eletrencefalografia em tais circunstâncias se torna mais evidente, quando se lembra que em muitos dêsses casos a arteriografia não é possível ou não é satisfatória, ou ainda que a ventriculografia é desaconselhada por ser considerada traumatizante ou é dificultada pela redução e deslocamento dos ventrículos em face do intenso edema cerebral ${ }^{8}$. Este ponto de vista otimista em relação ao diagnóstico eletrencefalográfico dos abscessos cerebrais é, em geral, partilhado pela maioria dos autores.

$\dot{E}$ fato proeminente em todos os relatos sôbre a eletrencefalografia (EEG) dos abscessos cerebrais a afirmação de que os traçados são sempre anormais (Walter ${ }^{13}$, Schwabb e Carter ${ }^{12}$, Courjon e Corriol ${ }^{3}$, Farbrot ${ }^{6}$, Ziegler e Hoefer $\left.{ }^{15}\right)$. Nos poucos casos com EEG normal os abscessos estavam situados no cerebelo (Schwabb e Carter ${ }^{11}$ ), ou se tratava de abscesso já em involução $\left(\operatorname{Cohn}^{5}\right)$.

Entre as anormalidades eletrencefalográficas mais citadas assinalam-se as ondas delta bastante lentas de elevado potencial e focais, as ondas delta difusas não tão lentas nem proeminentes em seu potencial, e, raramente, a depressão do ritmo de base, isolada ou em conjunção com as demais anormalidades.

Trabalho do Serviço de Neurologia da Escola Paulista de Medicina (Prof. Paulino W. Longo). Apresentado ao III Congresso Latino-Americano de Eletrencefalografia e Neurofisiologia Clinica, Medelin (Colômbia). * Chefe de Clinica; Livre-Docente de Clínica Neurológica na Fac. Med. da Univ. de São Paulo; atualmente Catedrático de Clínica Neurológica na Fac. Med. de Ribeirão Preto. ** Chefe de Clinica Neurocirúrgica. ${ }^{* * *}$ Assistente. 
As ondas delta bastante lentas são unânimemente assinaladas. Em geral estão sediadas em área circunscrita, adjacente ao abscesso, e ocorrem muito precocemente. Para Farbrot ${ }^{6}$, êste detalhe constituiu o elemento que permitiu diagnóstico eletrencefalográfico correto em seus 7 casos, todos bem comprovados. Do mesmo modo pensam Ziegler e Hoefer is que, em 28 casos, encontraram 14 com tais manifestações; isso mesmo foi assinalado por Courjon e Corriol ${ }^{3}$, Puech, Lerique-Koechlin ${ }^{10}$, Cobb ${ }^{2}$ e Walter ${ }^{13}$. Êste último, pioneiro da descrição do EEG nos abscessos cerebrais, é tão entusiasta de seus resultados que afirma ser absolutamente imprescindivel êste exame em todos os casos de processos purulentos na garganta, no nariz e nos seios paranasais, para se poder afirmar ou infirmar uma suspeita de abscesso cerebral. Pine, Atoynatan e Margolis ${ }^{9}$, dão proeminência a êste tipo de alterações, o qual esteve presente em 8 de seus 18 casos.

Além das ondas delta, as alterações difusas do traçado em todo um hemisfério ou, por vêzes, em ambos, são encontradiças. Isto, naturalmente, se deve à fase do processo em que o paciente é examinado, compreendendo-se fàcilmente que, nos primeiros dias, quando a moléstia é ainda um processo encefalítico difuso, as alterações difusas sejam predominantes no EEG, tendendo elas a predominarem localmente quando o abscesso vai se formando e se encistando $\left(\mathrm{Cobb}^{2}\right)$.

Já no tocante à depressão da atividade rítmica cerebral de base diferem um tanto as opiniões, predominando as dos que afirmam ser ela um achado raro. Entre êstes se encontram Williams e Reynell ${ }^{14}$, que apresentam um material de 50 casos com depressão focal do ritmo, entre os quais sòmente um era devido a abscesso e, assim mesmo, extradural. Da mesma opinião são Puech e Lerique-Koechlin ${ }^{10}$. Já Courville ${ }^{4}$ encontrou depressão focal ao nível do abscesso em 3 de seus 6 casos verificados; Pine, Atoynatan e Margolys 9 encontraram depressão em 5 dos seus casos, 4 dos quais se referiam a abscessos no lobo occipital.

Revisão bibliográfica quase completa sôbre EEG nos abscessos cerebrais é apresentada por Pine, Atoynatan e Margolis ${ }^{9}$, pelo que nos dispensamos de fazê-la. As melhores estatísticas são as dêstes próprios autores (18 casos, sendo 7 verificados pela autópsia e 11 pela cirurgia), de Ziegler e Hoefer ( 28 casos verificados por operação ou pela autópsia), de Pennybacker (20 casos), de Schwabb e Carter (15 casos), de Farbrot ( 7 casos) e de Walter ( 8 casos).

No presente trabalho relatamos estudos eletrencefalográficos em 22 pacientes com abscessos cerebrais. Dêsses 22 pacientes, em 20 o exame eletrencefalográfico foi feito antes da intervenção; dêste grupo de 20 doentes, 17 foram seguidos clínica e eletrencefalogràficamente durante vários meses após a intervenção. Nos dois últimos doentes de nossa série não pôde ser feito o exame eletrencefalográfico antes da intervenção; nestes dois casos, entretanto, também houve seguimento clínico e eletrencfalográfico.

Dividimos a exposição em duas partes: na primeira apresentaremos 20 casos nos quais pudemos fazer exames eletrencefalográficos prévios; na se- 
gunda apresentaremos 17 casos (15 com EEG pré e pós-operatório e 2 com EEG pós-operatório) que seguimos com exames clínicos e eletrencefalográficos sucessivos.

\section{RESULTADOS DO EEG PRÊ-OPERATÓRIO}

Esses resultados reafirmam os da literatura sôbre a incidência de anormalidades no EEG nos abscessos cerebrais, sôbre o seu tipo e valor diagnóstico localizatório, assim como permitem ressaltar a depressão local do ritmo de base como elemento de diagnóstico.

Nosso material consiste em 20 casos, todos com estudo eletrencefalográfico feito prèviamente a qualquer manipulação neurocirúrgica. Em todos os casos foi feito o exame arteriográfico ou ventriculográfico. Em todos o diagnóstico foi confirmado pela punção do abscesso ou pela intervenção cirúrgica. O exame eletrencefalográfico foi feito com aparêlho Grass, 8 canais (modêlo III D), sendo colocados 17 a 19 eletrodos de rotina, com tomadas bipolares sucessivas ou tomadas de referência comum (referência comum, orelha ou C vértex), conforme a técnica que usamos de rotina e que é a mesma adotada no Montreal Neurologic Institute.

Nossos resultados foram bastante objetivos e, até certo ponto, uniformes. As ondas delta 0,5 a $1,5 \mathrm{c} / \mathrm{s}$ e de potencial médio 150 a $250 \mathrm{mV}$, em surtos, com projeções relativamente focais, apareceram de modo bastante evidente. As figuras 1 e 2 mostram exemplos de casos dêste tipo. Estas ondas delta em alguns casos se mostraram em meio de um traçado de base inteiramente normal, em outros, em traçados inteiramente constituídos por ondas delta, algumas de 2 a $3 \mathrm{c} / \mathrm{s}$ e outras de 4 a $6 \mathrm{c} / \mathrm{s}$, difusas em extensas áreas de um ou de ambos hemisférios. O exemplo da figura 1 é bastante frisante, pois mostra que essas ondas delta difusas, representativas do edema cerebral generalizado, desapareceram minutos após a injeção endovenosa de solução hipertônica, restando sòmente as ondas delta 0,5 a $1,5 \mathrm{c} / \mathrm{s}$, localizadas em área correspondente à sede do abscesso e à sua vizinhança imediata.

Outro elemento proeminente em nossos casos foi a depressão focal do ritmo de base. Este elemento tem maior valor localizatório do que as próprias ondas delta acima referidas, pois que êle depende diretamente do abscesso, enquanto aquelas significam sofrimento do parênquima nervoso nas vizinhanças do processo. Esta depressão do ritmo de base aparece nìtidamente na figura 2, nas áreas que correspondem ao abscesso, enquanto que nas áreas circunvizinhas há um ritmo da base associado a ondas delta.

Entretanto, tivemos casos, felizmente raros, cujo diagnóstico foi bem mais difícil. A figura 3 é disso exemplo frisante, mostrando os resultados eletrencefalográficos em caso de abscesso no qual erramos o diagnóstico topográfico e mesmo o hemisfério em que se encontrava a lesão. Pela presença de ondas delta no lobo temporal esquerdo, julgamos ser essa a sede do abscesso, o qual, como o demonstraram o exame arteriográfico e a intervenção cirúrgica, estava localizado em área heterolateral, isto é, têmporo-parietal direita; a arteriografia, feita bilateralmente, mostrou não haver abscesso à esquerda. 
Explicamos essa ocorrência pela contrapressão da corticalidade contra a tábua óssea craniana. Tivemos experiência semelhante em outra ocasião com um paciente portados de hematoma paríeto-temporal, apresentando também ondas delta em áreas homólogas do hemisfério oposto. Eis alguns dos motivos pelos quais pensamos ser a depressão focal do ritmo de base elemento mais seguro e menos enganoso que as ondas delta para o diagnóstico topográfico.

Todos os casos foram estudados detalhadamente, procurando-se correlacionar os dados de diagnóstico topográfico fornecidos pelo EEG (sede principal das ondas delta muito lentas e de elevado potencial, depressão do ritmo cerebral de base) com os elementos clínicos e paraclínicos (síndrome neurológica, imagem ventriculográfica e arteriográfica) e com a comprovação cirúrgica da localízação do abscesso. Dispensâmo-nos de apresentar o quadro geral com todos êstes elementos, não só por ser tècnicamente difícil, como porque, a análise fracionada dos elementos de interêsse, em quadros parcélados, preenche perfeitamente as finalidades dêste trabalho. Assim, no quadro 1 expomos os resultados eletrencefalográficos globais; no quadro 2, procuramos correlacionar a topografia indicada pelo EEG com aquela fornecida pelos dados clínicos e neurocirúrgicos.

Ondas delta focais 0,5 a $3 \mathrm{c} / \mathrm{s} \ldots \ldots \ldots \ldots \ldots \ldots \ldots \ldots \ldots . \ldots \ldots$ casos

Depressão focal do ritmo de base .............. 11 casos

Alterações difusas do ritmo de base, unilateral ........ 11 casos

Alteraçōes difusas do ritmo de base, bilateral ........ 3 casos

Foco epileptógeno $\ldots \ldots \ldots \ldots \ldots \ldots \ldots \ldots \ldots \ldots \ldots \ldots \ldots \ldots \ldots \ldots \ldots$ casos

Ondas delta focais no hemisfério controlateral ....... 2 casos

Quadro 1 - Tipos de alteracões eletrencefalográficas em 20 pacientes com abscesso cerebral.

Chama atenção, no quadro 1, a existência de anormalidades eletrencefalográficas em $100 \%$ dos casos examinados. Entre essas anormalidades merece especial atenção a freqüência do aparecimento de ondas delta 0,5 a 3 c/s (19 casos), e depressão do ritmo de base (11 casos). As ondas delta muito lentas e de elevado potencial dependem, naturalmente, do sofrimento agudo do parênquima nervoso adjacente ao abscesso, enquanto que a depressão da atividade elétrica cerebral de base deve estar correlacionada à presença do próprio abscesso, inibindo ou ocupando lugar de córtex cerebral.

Em segundo plano, entre os elementos evidenciados pelo EEG, encontramos os sinais de sofrimento difuso de um hemisfério (11 casos) em contraste com a relativa raridade de sinais de sofrimento em ambos hemisférios (3 casos). Isto, até certo ponto, pode ser mais um elemento para o diagnóstico diferencial com certos tumores cerebrais de evolução aguda.

Merece particular destaque, neste material, assinalar a raridade de aparecimento de sinais de foco epileptógeno ativo, raridade esta maior que a 
presença de crises convulsivas nesses pacientes; verificou-se foco eletrencefalogràficamente ativo sòmente em dois casos, enquanto que a história mórbida assinalava 6 pacientes com crises convulsivas. Isto tem importância porque difere radicalmente do que ocorre com os traçados eletrencefalográficos dêsses mesmos pacientes após a cura do processo mórbido agudo. Dentre os 17 casos seguidos, foram observados 10 com foco epileptógeno ativo, incluindo os dois que o apresentavam no pré-operatório; em 8 dêsses pacientes a sindrome convulsiva esteve presente, como veremos adiante. Pensamos que a própria natureza inflamatória aguda dêste processo seja a razão da não formação dos focos definidos, muito mais fàcilmente compreensiveis nos processos crônicos e com cicatrizes meningocorticais, tal como soem aparecer na fase de seqüelas dêstes processos.

\begin{tabular}{|c|c|c|c|c|}
\hline Caso & $E E G$ & $\begin{array}{c}\text { Sintomatologia } \\
\text { clinica }\end{array}$ & $\begin{array}{l}\text { Arteriografia ou } \\
\text { ventriculografia }\end{array}$ & $\begin{array}{l}\text { Intervençio } \\
\text { cirúrgica }\end{array}$ \\
\hline 1 & $\mathrm{O}_{2}$ & \pm & $\mathrm{PO}$ & PO \\
\hline 2 & $\mathrm{~F}_{3}$ & \pm & $\mathrm{F}_{3}$ & $\mathrm{~F}_{3}$ \\
\hline 3 & $F_{4}-F_{s}$ & - & $F_{8}$ & $F_{8}$ \\
\hline 4 & $F_{7}-T_{3}$ & + & $\mathbf{T}_{3}$ & $\mathrm{~T}_{3}$ \\
\hline 5 & $\mathrm{Pf}_{1}-\mathrm{F}_{3}$ & \pm & $\mathbf{F}_{3}$ & $\mathrm{~F}_{3}$ \\
\hline 6 & $\mathrm{~F}_{3}-\mathrm{C}_{3}$ & \pm & $\mathrm{F}_{3}$ & $\mathrm{~F}_{3}$ \\
\hline 7 & Hemisfério D. & 一 & $\mathrm{O}_{2}$ & $\mathrm{PO}_{2}$ \\
\hline 8 & $T_{4}-T_{6}$ & \pm & $\mathrm{T}_{4}$ & $T_{4}$ \\
\hline 9 & $\mathrm{~F}_{4}-\mathrm{C}_{4}-\mathrm{F}_{8}$ & + & $F_{8}$ & $\mathrm{~F}_{\mathrm{s}}$ \\
\hline 10 & $P_{t}-T_{6}$ & - & $\mathrm{T}_{6}-\mathrm{O}_{2}$ & $\mathrm{~T}_{6}-\mathrm{O}_{2}$ \\
\hline 11 & $\mathrm{C}_{3}-\mathrm{P}_{3}$ & + & $\mathrm{FP}_{3}$ & $\mathrm{FP}_{3}$ \\
\hline 12 & Hemisfério D. & - & $F_{s}$ & $\mathrm{~F}_{8}$ \\
\hline 13 & $P_{4}-T_{6}$ & - & $\mathrm{T}_{n}$ & $\mathrm{~T}_{6}$ \\
\hline 14 & - & \pm & $\mathrm{T}_{3}$ & $\mathrm{~T}_{3}$ \\
\hline 15 & - & \pm & $\mathrm{F}_{3}$ & $\mathrm{~F}_{3}$ \\
\hline 16 & $F_{3}-F_{7}$ & + & $\mathbf{F}_{3}$ & $\mathbf{F}_{3}$ \\
\hline 17 & $\mathrm{FC}_{3}$ & \pm & $\mathrm{FP}_{4}$ & $\mathrm{FP}_{4}$ \\
\hline 18 & $\mathrm{~F}_{7}-\mathrm{T}_{3}$ & \pm & $\mathrm{T}_{3}$ & $\mathbf{T}_{3}$ \\
\hline 19 & $\mathrm{~F}_{3}-\mathrm{C}_{i}$ & \pm & $F_{3}$ & $F_{i}$ \\
\hline 20 & $F_{3}-F_{7}-T_{3}$ & - & $\mathrm{T}_{3}$ & $\mathrm{~T}_{:}$ \\
\hline 21 & $\mathrm{~F}_{\mathrm{s}}-\mathrm{F}_{\mathrm{z}}$ & - & $F_{3}-F_{7}$ & $F_{3}-F_{7}$ \\
\hline 22 & $F_{7}-T_{5}-T_{5}$ & \pm & $\mathbf{T}_{3}$ & $\mathbf{T}_{3}$ \\
\hline
\end{tabular}

Quadro 2 - Correlaçăo do diagnóstico topográfico sugerido pelo EEG com os elementos fornecidos pela sintomatologia clínica e pelo exame radiológico (arteriografia ou ventriculografia), assim como com os achados neurocirúrgicos. Nos casos 14 e 15 não foi feito EEG antes da intervenção cirurrgica. Legenda - Sintomatologia clinica: + suficiente para o diagnóstico topográfico; \pm apenas sugestiva; - ausente. As letras indicam lobos cerebrais: $F$ frontal; $P$ parietal: $T$ temporal; $O$ occipital. $O s$ numeros que acompanham essas letras indicam hemisfério direito (números impares) ou esquerdo (pares). Mesma simbolizacio que a usada no Montreal Neurologic Institute. 
Passando do diagnóstico do tipo do processo mórbido para o diagnóstico topográfico, expomos no quadro 2 os resultados nos 20 pacientes em que tivemos ocasião de fazer EEG pré-operatório, antes de qualquer manipulação neurocirúrgica do paciente. Comparamos aí os dados fornecidos pelo EEG para a localização do abscesso com os fornecidos pelos exames radiográficos contrastados (arteriografia e/ou ventriculografia) e pela intervenção cirúrgica (trepanopunção e extirpação). Nesse quadro ainda assinalamos os elementos fornecidos pela clínica que permitiram ou não o diagnóstico localizatório. Os dados fornecidos pelo EEG aqui assinalados são os que nos levaram a um relatório de diagnóstico topográfico no dia $\mathrm{\epsilon m}$ que o exame eletrencefalográfico foi feito (veremos adiante e comentaremos, que êsse diagnóstico foi errôneo em dois pacientes!; assinalamos, outrossim, neste quadro, só os elementos eletrencefalográficos que nos serviram para firmar o diagnóstico topográfico, não mencionando mais aquêles sinais difusos de sofrimento do hemisfério cerebral, já assinalados.

Da análise dêsse quadro ressalta o seguinte: a) em 16 dos 20 pacientes a conclusão diagnóstica eletrencefalográfica coincidiu topogràficamente com aquela da real localização do abscesso; b) em dois pacientes (casos 1 e 17) assinalamos uma topografia aproximadamente certa, embora no hemisfério oposto; c) em dois pacientes o eletrencefalograma mostrou sòmente sinais de processo lesional, com sofrimento cerebral difuso, no hemisfério cerebral correspondente ao abscesso, sem fornecer elementos localizatórios definidos.

Êsses resultados são, a nosso ver, bastante satisfatórios. Os dados eletrencefalográficos em que nos baseamos - o local de incidência máxima de ondas delta do mais elevado potencial e, particularmente, o de depressão focal do ritmo de base - sāo realmente úteis para o diagnóstico topográfico. Nos dois casos em que erramos o lado, o reestudo ulterior (a possibilidade da existência de abscessos em ambos hemisférios foi afastada pela arteriografia bilateral [vide, para exemplo, o caso da figura 3]), revendo o traçado eletrencefalográfico, mostrou haver depressão focal do ritmo de base na área do hemisfério oposto àquele em que as ondas delta predominavam, isto é, em área correspondente ao abscesso. Corrigimos, assim, daí por diante, nosso raciocínio diagnóstico, dando maior valor à depressão focal do ritmo de base que às próprias ondas delta. Em nossa experiência houve, pois, dois casos em que a presença de ondas delta não foi elemento seguro para diagnóstico localizatório.

Com tais elementos podemos concluir pela excelência do método eletrencefalográfico como meio auxiliâr de diagnóstico, dando elementos de suspeita da existência do abscesso cerebral e fornecendo sinais localizatórios; quando menos, êste exame fornece elementos para indicar qual o hemisfério lesado, fato êste de grande alcance quando se tratar de pacientes em coma, sem sinais clínicos localizatórios; o EEG permite, no mínimo, orientar quanto ao lado no qual deva ser feita a arteriografia. O EEG deve, pois, ser feito em todos os casos em que haja a mais leve suspeita de afecção purulenta cerebral. Nossos resultados e nossa opinião coincidem com a maioria dos que se ocuparam do assunto. 


\section{RESULTADOS DO EEG NO SEGUIMENTO DE DOENTES PORTADORES DE ABSCESSOS CEREBRAIS TRATADOS}

É sabido que a evolução dos abscessos cerebrais, apesar de espetacularmente modificada para melhor com o advento da antibioticoterapia, continua ainda a ser algo sombria. Tal pessimismo decorre principalmente da freqüência com que ulteriormente aparece a epilepsia, independentemente do método cirúrgico ou conservador utilizado para o tratamento. Compreende-se fàcilmente êste fato, pois o processo que leva ao abscesso cerebral é, inicialmente, a meningoencefalite purulenta; mesmo quando a evolução é a melhor possivel, tendendo para o encistamento, o processo deixa cicatrizes meningoencefálicas que poderão constituir focos irritativos e, portanto, epileptógenos. Daí o interêsse em obter o maior número possível de elementos que permitam avaliar o prognóstico e orientar a terapêtica depois de passada a fase aguda da moléstia. Os dados fornecidos pelos eletrencefalogramas são bastante úteis nesse sentido.

A apresentação dêstes resultados comparativamente aos elementos ciínicos colhidos na observação dêsses pacientes, em seqüência, tem por finalidade avaliar os dados fornecidos pelo EEG em relação ao prognóstico. Os dados clínicos são, neste trabalho, ùnicamente elementos de referência.

Vimos, no capitulo anterior, que o EEG revela, precocemente e em $100 \%$ dos casos alterações bastante evidentes que, aliadas aos elementos clínicos permitem o diagnóstico presuntivo de abscesso cerebral. A arteriografia é o elemento de confirmação e de precisão do diagnóstico topográfico, e. portanto, o elemento básico de orientação da terapêutica neurocirúrgica.

Da mesma forma, o estudo eletrencefalográfico em série permite o estudo da evolução do abscesso, indicando a regressão progressiva do processo agudo e a evoluçăo para a cura, com ou sem seqüelas.

Orientamos nossas pesquisas neste sentido, procurando fazer traçados re:petidos nos dias subseqüentes ao tratamento médico-cirúrgico (punção e extirpação em bloco em 15 casos, sòmente punções repetidas em 2 casos, colateralmente à terapêutica antibiótica) e, depois, em intervalos mais longos, que variaram de 1 a 24 meses, alguns casos tendo sido seguidos até 48 e 62 meses depois.

Assim, o estudo em seqüência foi feito em 17 pacientes, dos quais em 15 o estudo eletrencefalográfico pôde ser feito antes e depois da intervenção; em 2 casos não tínhamos, por razões várias, o traçado pré-operatório. No quadro 3 pode ver-se os resultados que obtivemos.

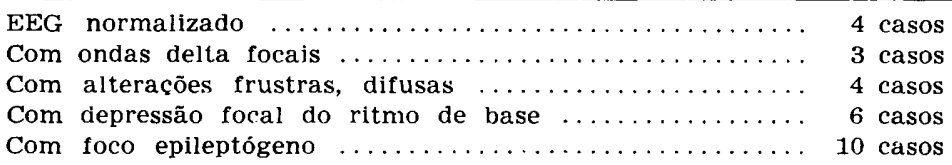

Quadro \$ - Resultados do tratamento médico-cirúrgico sôbre as alteracões eletrencefalográficas em 17 pacientes. 


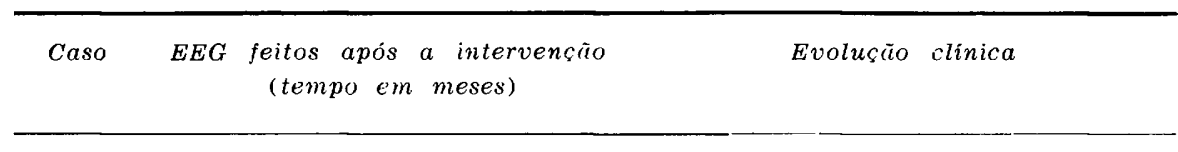

Pacientes com persistência de ondas delta

$5 \quad 1$ e 2

101 , desap. depois de 2 meses

113

Pacientes com depressīo focal do ritmo de base

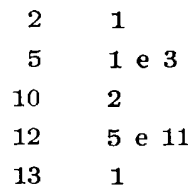

Pacientes com EEG normalizado

46,15 e 28

$10 \quad 2$ e 3

1760

183

$9 \quad 1,4,14$ e 15

aparecimento de foco depois de 19,22 e 23

165

aparecimento de foco depois 25,33 e 60

Crises GM

Individuo normal

Individuo normal

Bradipsiquismo

Individuo normal

Individuo normal
Torpor, apatia, crise GM

Individuo normal

Hemiparesia direita, afasia, convulsōe

Hemiparesia. Afasia frustra

Convulsōes, hemiparesia

Paresia braquiofacial

Crises jacksonianas

Crises jacksonianas

Pacientes com foco epileptógeno verificado

$1 \quad 32$

$2 \quad 5,27$ e 33

53

$7 \quad 37$ e 42

$8 \quad 1,11$ e 44

919,22 e 23

$14 \quad 3,41$ e 45

$15 \quad 18,19,20$ e 29

$16 \quad 25,33$ e 60

$22 \quad 3$
Hemiparesia. Crises jacksonianas

Nāo mais distúrbios afásicos. Crises jacksonianas

Crises GM

Hemianopsia

Individuo normal

Crises jacksonianas

Crises jacksonianas

Distúrbios do comportamento. Crises jacksonianas

Irises jacksonianas

Crises GM

Quadro 4 - Dados comparativos entre a sintomatologia clinica e as alteracões eletrencefalográficas, tomadas simultâneamente $e$ em épocas diversas, a partir do tratamento médico-cirirgico. 
As figuras 4 e 5 mostram alguns dos aspectos eletrencefalográficos obtidos na seqüência dêsses casos, particularmente em relação ao rápido desáparecimento, em geral, das ondas delta, à persistência de alterações frustras ou de depressão do ritmo de base, assim como o aspecto predominante do aparecimento, mesmo tardio, dos sinais eletrencefalográficos de foco epileptógeno ativo.

$\mathrm{Na}$ análise dos traçados obtidos na seqüência dêstes casos consideramos sòmente as alteraçōes eletrencefalográficas assinaladas a partir de 30 dias após a intervenção terapêutica, já que, nos primeiros dias que se seguem ao ato operatório, são extremamente variáveis essas alterações, dependendo de fatôres vários naturalmente condicionados ao ato cirúrgico e aos eventos pós-operatórios; as alterações eletrencefalográficas, persistentes depois de 30 dias, dizem mais respeito à evolução do próprio abscesso.

No quadro 4 procuramos sintetizar os elementos clinicos apresentados pelos 17 pacientes cujos resultados eletrencefalográficos figuram no quadro 3 , na época em que os exames foram feitos; compara-se, assim, o quadro clínico e o quadro eletrencefalográfico em épocas diversas, sinalizadas em meses a partir do ato operatório.

Assim, registramos a persistência de ondas delta em 3 pacientes, a depressão da atividade elétrica cerebral de base em áreas relativamente restritas em 5, enquanto que a normalização do traçado se processou em 6 pacientes (dos quais, a evolução por mais de 15 meses mostrou persistirem normais sòmente 4). O achado mais significativo foi, entretanto, o aparecimento de sinais de foco epileptógeno ativo em 11 casos (dos quais sommente em 2 havia tal foco em período pré-operatório).

A persistência pós-operatória de ondas delta foi verificada em número restrito de casos e por tempo relativamente curto (1 mês no caso 10 , tendo desaparecido em exame feito 2 meses depois, 2 e 3 meses nos casos 5 e 11).

A depressão de atividade de base, em áreas topogràficamente relacionadas com o abscesso, depressão esta que estava evidente no exame pré-operatório ou podia estar mascarada pela presença de outras anormalidades eletrencefalográficas, foi evidenciada em 5 pacientes.

É digno de nota que sòmente em 6 pacientes houve normalização do traçado, sendo que em 2 dêles houve, tardiamente, aparecimento de foco epileptógeno ativo. No caso 16 o aparecimento de foco epileptógeno foi verificado 25 meses depois da operação, e se mantinha ativo, em exames feitos 33 e 50 meses depois; neste caso o EEG, feito 5 meses depois da operação, era normal; a evolução clínica foi paralela à eletrencefalográfica; o aparecimento de crises convulsivas tão tardiamente em paciente que estava relativamente bem, foi o que nos levou a novo EEG. No caso 9, entretanto, já havia foco convulsiógeno ativo, de projeção centroparietal direita, em correlação topográfica com o abscesso; tal foco desapareceu por completo em vários traçados feitos, respectivamente, 1, 4 e 15 meses após a intervenção, para reaparecer em exames feitos 19, 22 e 23 meses depois; a persistência 
estritamente focal dessas manifestações eletrencefalográficas, assim como a constância de crises clínicas de tipo bravais-jacksoniano na hemiface esquerda, nos levou à intervenção cirúrgica, sob contrôle eletrocorticográfico (fig. 5); esta intervenção isoladamente não teve efeitos úteis definitivos, restando atividade focal subcortical após extirpação, por sucção, do córtex comprometido; as manifestações clínicas e eletrencefalográficas foram controladas, ulteriormente, com terapêutica medicamentosa; o estudo detalhado dêste caso não é cabivel no âmbito dêste trabalho, ficando reservado para publicação ulterior relativa aos nossos casos de epilepsia focal cirùrgicamente tratados.
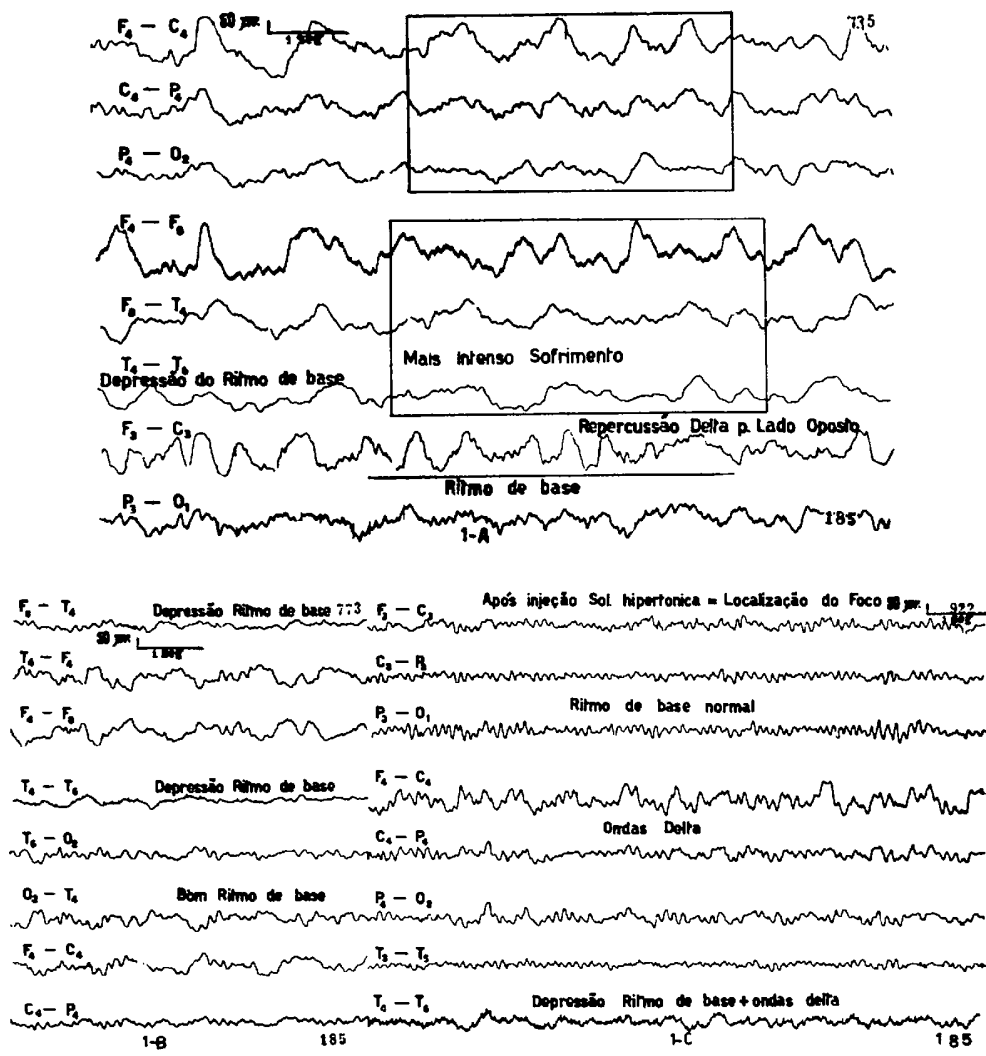

Fig. 1 - I. G. (caso 3). Abscesso temporal direito. Atividade elétricu cerebral de base quase totalmente substituída por ondas delta 10,5 a $1.5 \mathrm{c} / \mathrm{s}$; de potencial superior a $150 \mathrm{mV}$, principalmente no hemisféric direito $(A)$ : em $B$, nota-se mais nitidamente a depressão do ritmo de base em áreas temporais do hemisfério direito: em $C$ nota-se o efeito espetacular da injeção endovenosa de solução glicose $50 \%$, fazendo reaparecer o ritmo de base organizado em todo hemisfério esquerdo, assim como em grande parte do direito, deixando evidentes as ondas delta em $\mathrm{F}_{4}$ e $\mathrm{C}_{4}$ e a depressüo $\mathrm{cm} T_{4}$ (esta coincidente com o local do abscesso, aauelas em árcas circunvizinhas). 


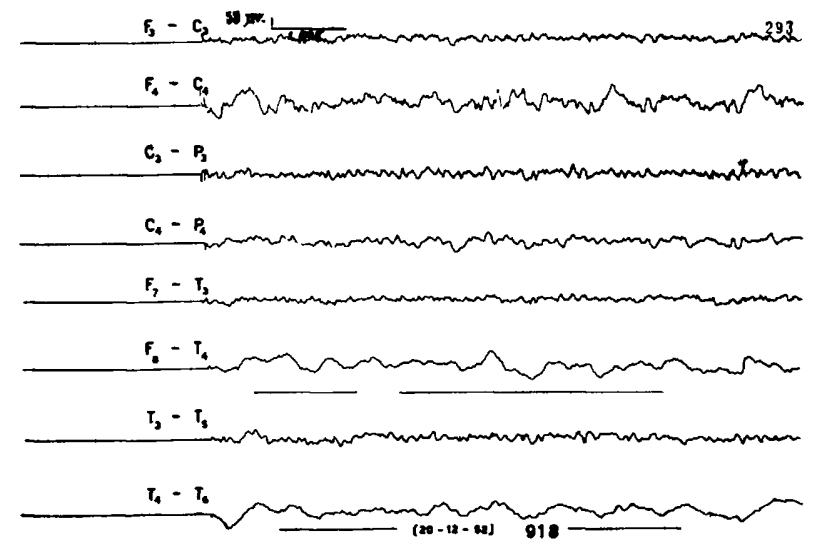

Fig. 2 - M. S. O. (caso 8). Abscesso temporal direito. Ondas delta $(0.5$ a $1.5 \mathrm{c} / \mathrm{s})$, com nitida depressão de ritmo do base nas áreas correspondentes ao abscesso $\left(F_{8}-T_{4}\right)$ e ondas (lelta (2 a $5 \mathrm{c} / \mathrm{s}$ ), em geral somadas ao ritmo de base nas áreas circunvizinhas $\left(\mathrm{F}_{4}-\mathrm{C}_{4}\right)$.

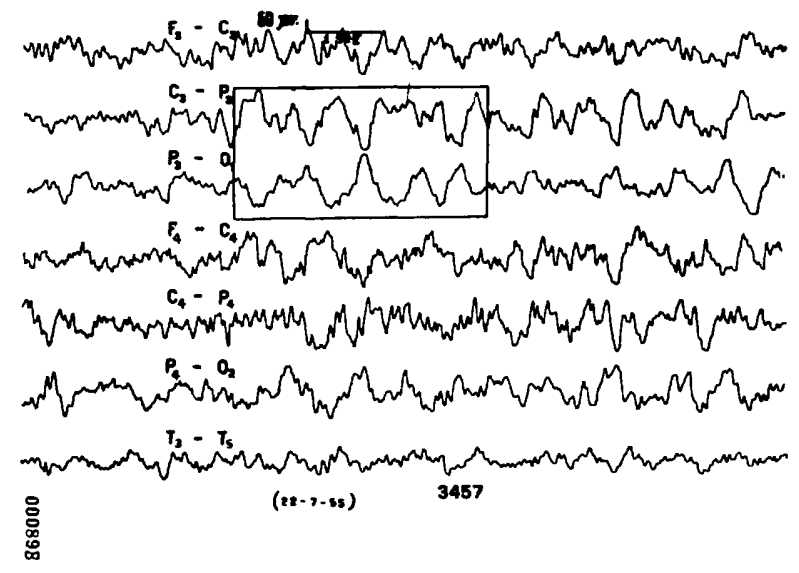

Fig. 3 - A. A. J. (caso 13). Abscesso temporal direito. Assinala-se surpreendentemente, ondas delta $(0,5$ a $1,5 \mathrm{c} / \mathrm{s}$ ) de potencial superior a $150 \mathrm{mV}$, em areas centroparietais esquerdas $\left(C_{3}-P_{3}\right)$, em meio de ondas delta 4 a $7 \mathrm{c} / \mathrm{s}$ difusas a ambos hemisférios. 


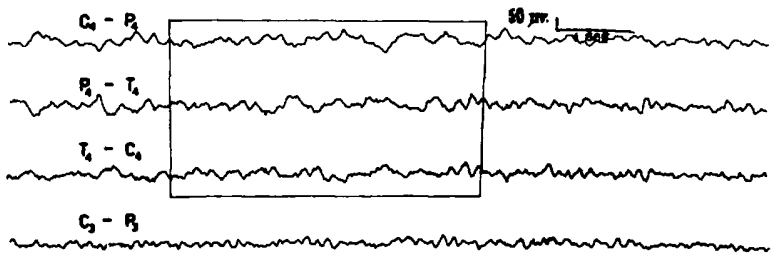

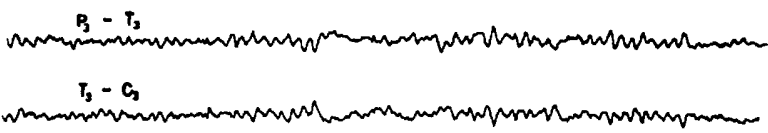

$F_{4}-F_{0}$

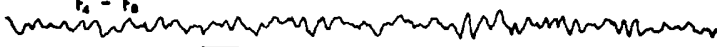

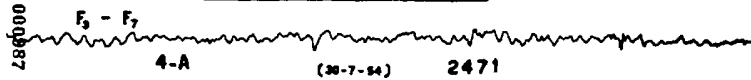

$C_{4}-P_{4} 5000,1$

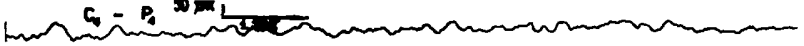

$P_{4}-O_{2}$

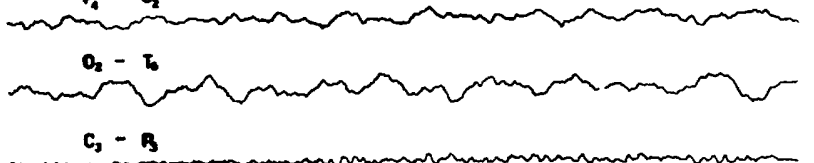

$P_{3}-\mathbf{0}_{1}$

0, - t

(s)

$F_{6}-\mathbf{C}_{0}$

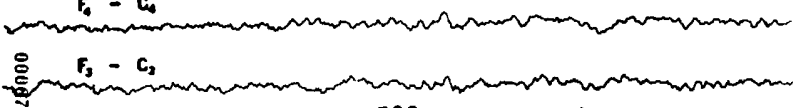

(21-8-84)

2638

4-B
Fig. 4 - M. G. R. (caso 10). Abscesso têmporo. (.ccipital direito. $E m A$, ondas delta $(0,5$ a 1,5 $c / s)$, nuaxime ern $C_{4}$ e $P_{4}$ : ondas delta, difusas na.; demais árcas do hemisfério direito; em $B$, ondas delia em $T_{\epsilon}$ e $O_{2}, 11$ dias após extirpacão cirúrgica do abscesso; em $C$, li. geira depressĩo da atividade de base $e$ ondas delta, ainda frustras, em $P_{4}-O_{2}, 21$ dias após operacão; em $D$, pràticamente normalização do tracado. Paciente curado.

(1)



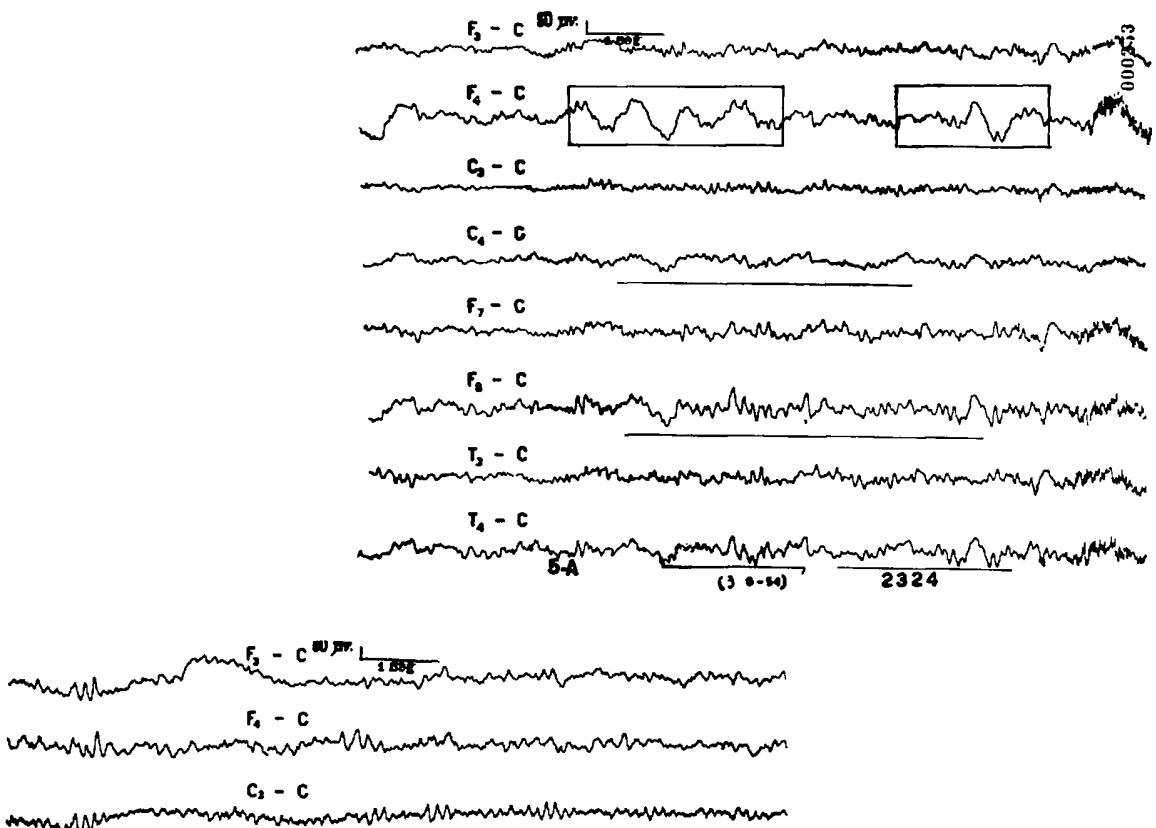

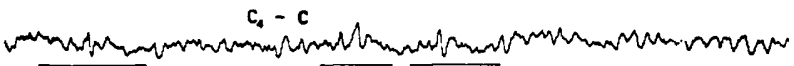

$P_{3}$ - C

Fig. $5(A, B, C)$ - Vide

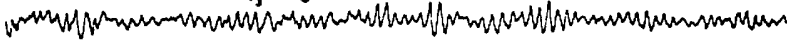
legenda na pág. seguinte.

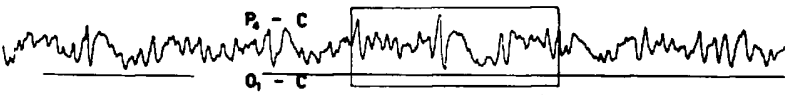

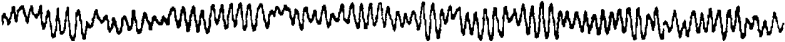

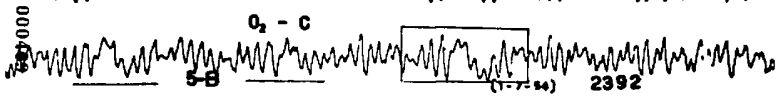

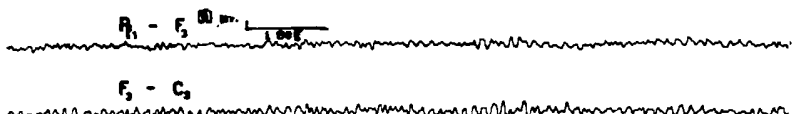

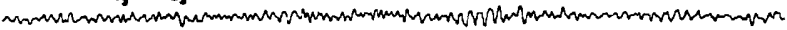

$$
C_{3}-P_{3}
$$

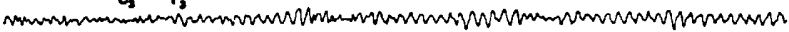

Miperpneia

$$
F_{4}-C_{4}
$$

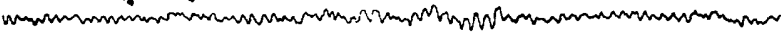

$C_{6}-P_{4}$

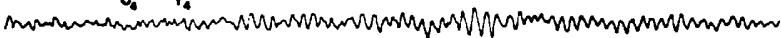

$f_{7}-T_{2}$

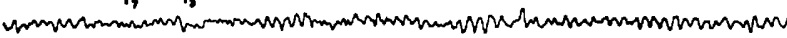

5-C



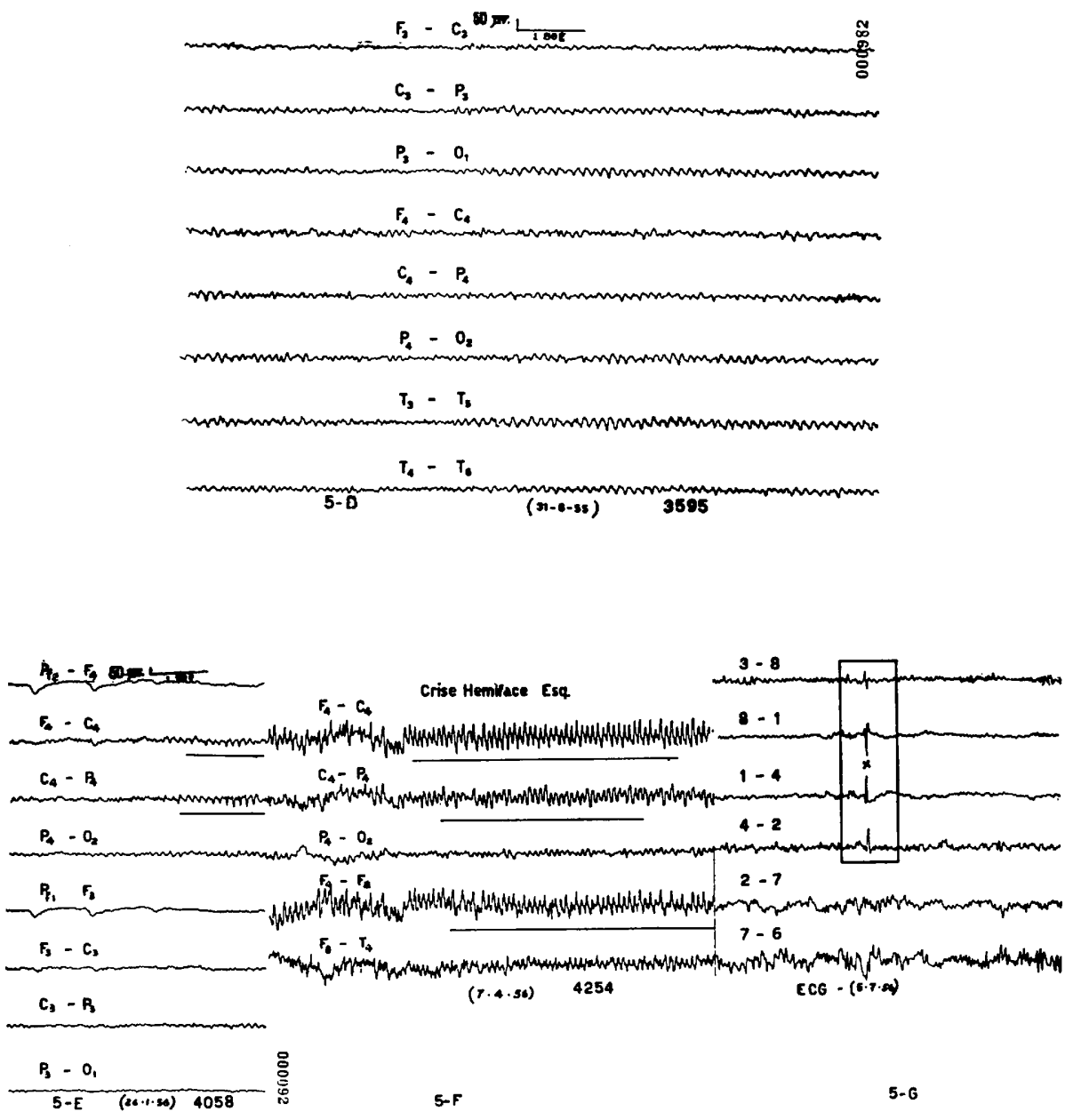

Fig. 5 - A. A. (caso 9). Abscesso frontal direito. Em A, ondas delta frustras, difusas a todo hemisfério direito e ondas delta $(0,5 \mathrm{a} 1,5 \mathrm{c} / \mathrm{s})$ em $F_{4} ;$ em $B$, ondas delta em $F_{4}, C_{4}$ e $P_{4}$, e foco de ondas "sharp" em $P_{4}$; em $C, E E G$ normal; em $D$, EEG normal 13 meses após cura do abscesso. O paciente continua tendo crises bravais-jacksonianas: em $E$, reaparecimento do foco ativo em $C_{4}-P_{4}, 19$ meses após. Crises freqüentes, foco $\mathrm{F}_{4}-\mathrm{C}_{4}$ : em $\mathrm{F}$ e em $\mathrm{G}$, espicula verificada nessa área, pela eletrocorticografia, por ocasião da intervenção cirúrgica visando o foco. 

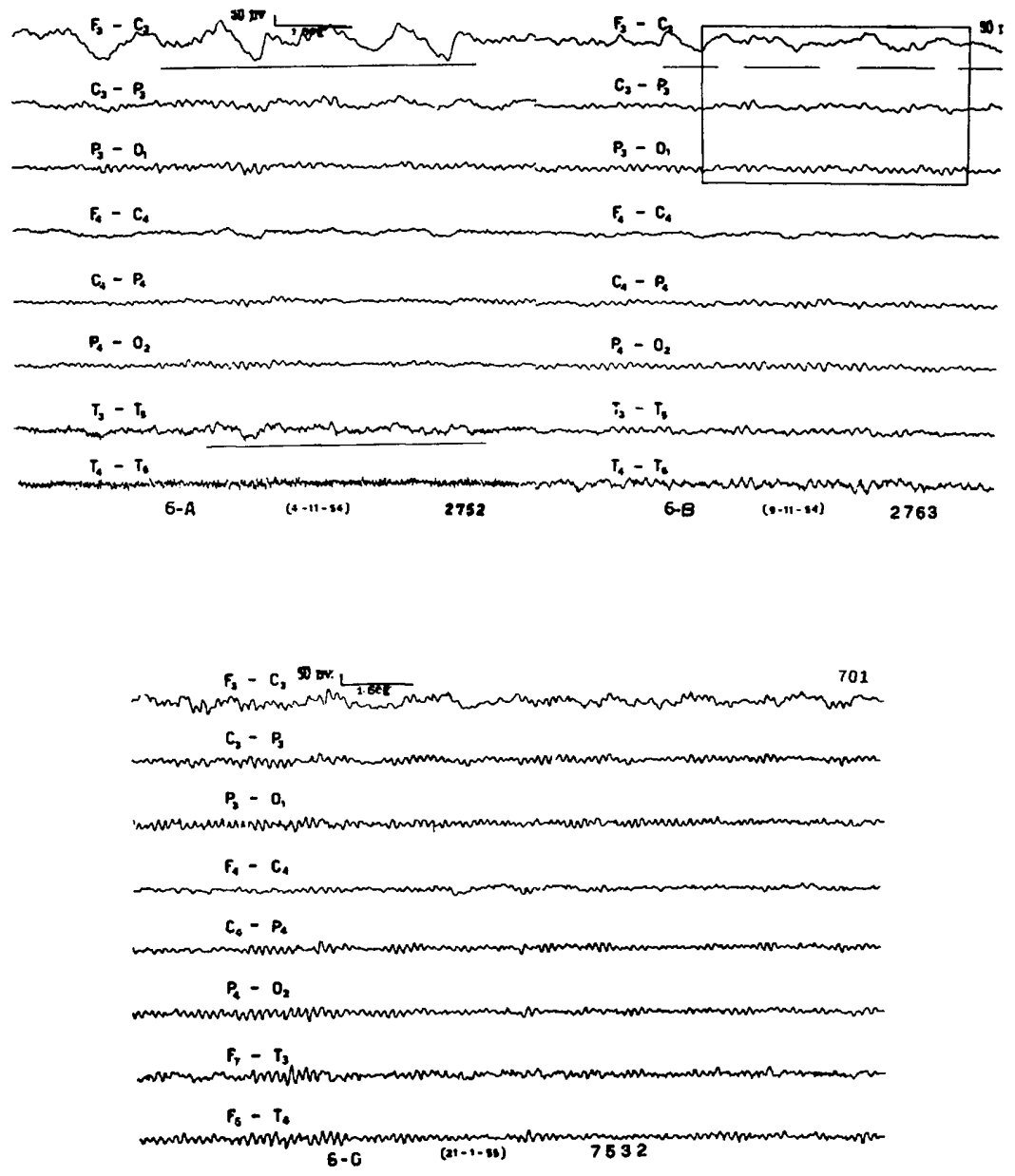

Fig. 6 - G. J. S. V. (caso 5). Abscesso frontal esquerdo. Em A, presenca de ondas delta $(0,5$ a $1,5 \mathrm{c} / \mathrm{s})$ de elevado potencial restritas a $F_{3}-C_{3}$ : em $B$, presença dessas alteraçōes, dois dias após esvaziamento do abscesso por punção; em $C, 3$ meses após extirpação cirúrgica do abscesso, ainda persistem. ondas delta em $\mathrm{H}_{3}-\mathrm{C}_{3}$, se bem que muito menos intensamente. 


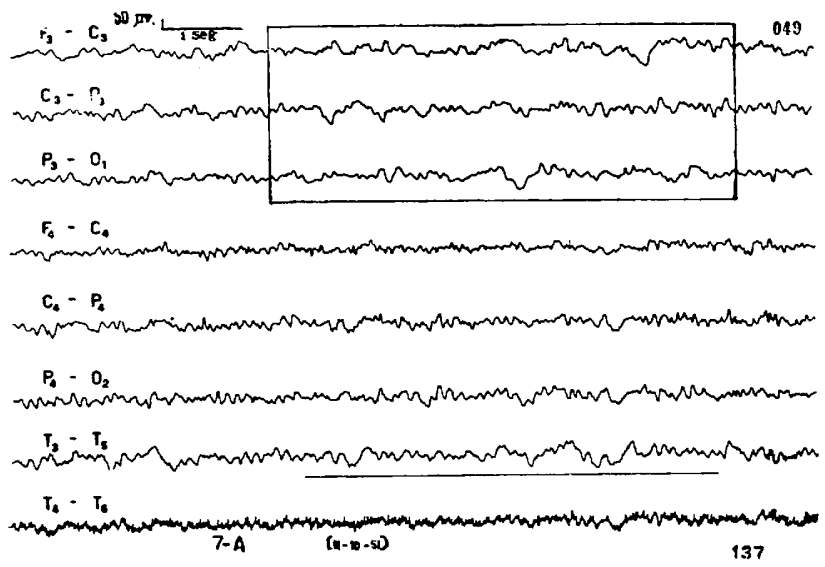

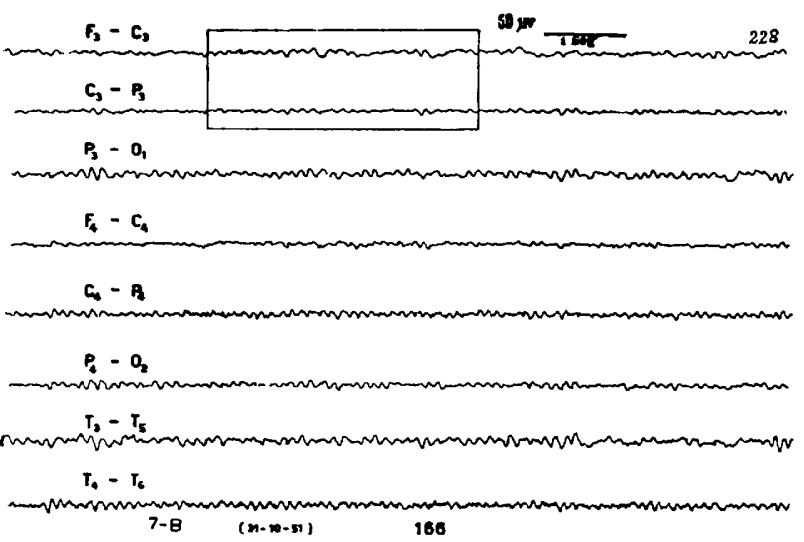

Fig. 7-A. A. (caso 2). Abscesso frontal esquerdo. Em A, ondas delta difusas a todo hemisfério esquerdo; em $B$, resta $7 i$ geira depressão de ritmo de base em extensa área do hemisfério esquerdo, 20 dias após operação; em $C$, exteriorizacão de atividade focal epileptógena entre $C_{3}$ e $P_{3}$. $P a-$ ciente com crises convulsivas de inicio bravaisjacksonianas há 18 meses.

$F_{4}-C_{4}=0 \mathrm{gr}$

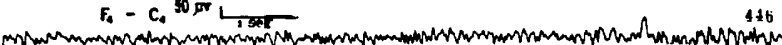

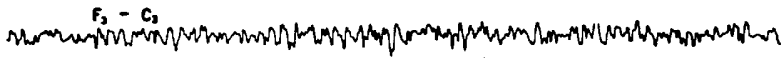

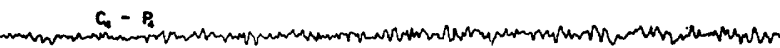

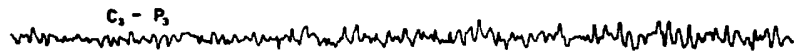

$P_{4}-\mathbf{O}_{2}$

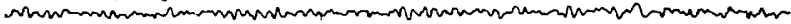

$\mathbf{P}_{\mathbf{3}}-\mathbf{O}_{\mathbf{1}}$

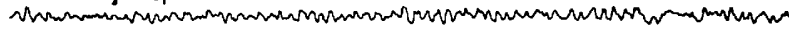

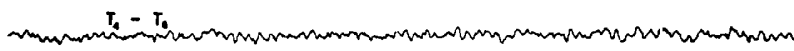

$T_{3}=T_{3}$

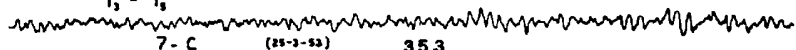




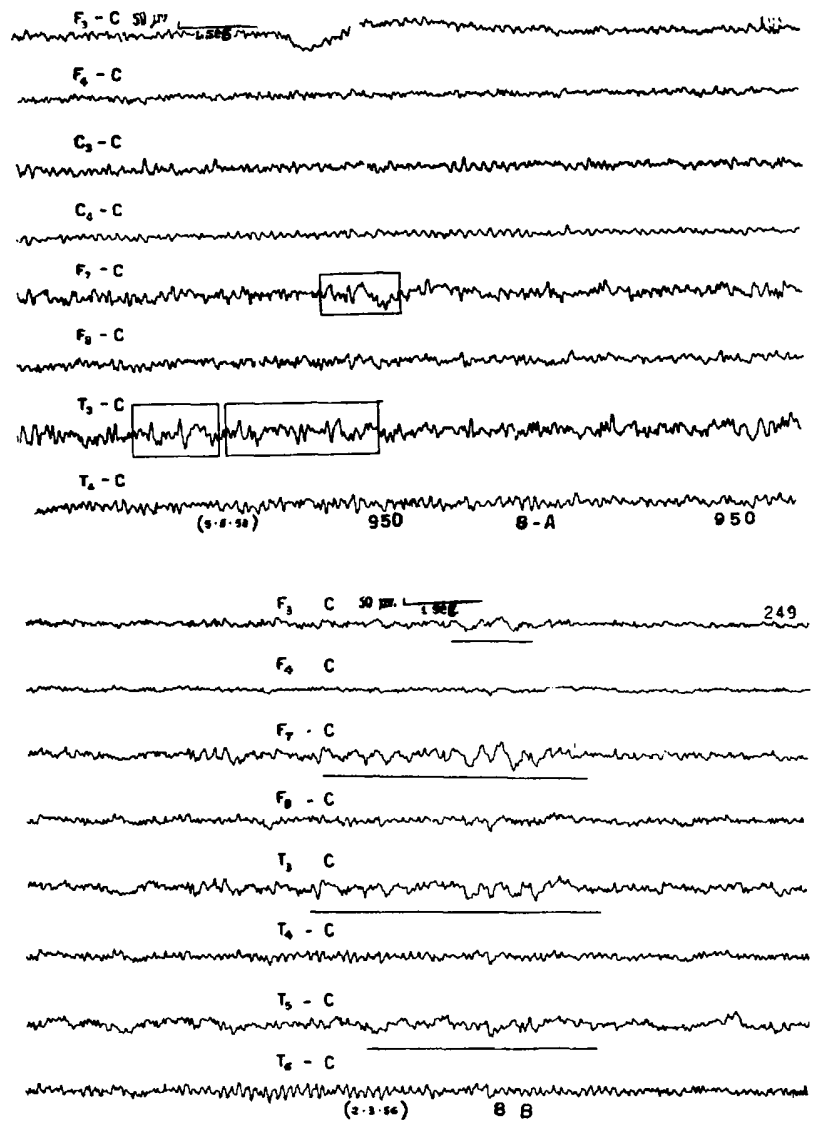

Fig. 8 - P. S. O. (caso 14). Paciente onerado de abscesso temporal esquerdo um ano antes. $E m T_{3}$ e áreas vizinhas, eclosão de surtos de disritmias por ondas "sharp" reiteradas. $O$ paciente apresentou epilepsia tipo jacksoniano u,m mês após a operaçũo.

Nos 4 pacientes restantes, nos quais persistiram traçados eletrencefalográficos normais, clìnicamente houve aparecimento de manifestações convuisivas, raras, sòmente em um (caso 4), enquanto que os demais (casos 10, 17 e 18) apresentaram seqüelas neurológicas frustras.

Sobressaem, em nossos resultados eletrencefalográficos de seqüência, os sinais de foco irritativo cerebral (quer por ondas "sharp" irregulares, algo lentas, quer por focos espiculares bem definidos [figs. 5, 8 e 9]). Em 10 dos nossos pacientes, dentre os 17 que tivemos oportunidade de seguir em periodo pós-operatório, tal eventualidade esteve presente, o que constitui uma incidência surpreendentemente elevada. 


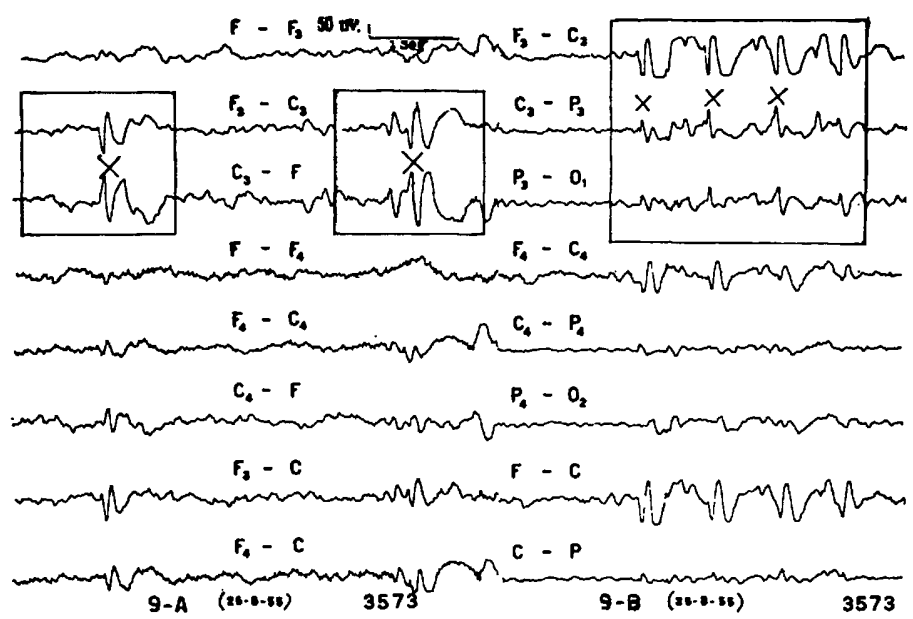

Fig. 9 - R. V. S. (caso 15). Paciente operado de abscesso frontal esquerdo há 2 anos. Crises Psm e bravais-jacksonianas. Em $A$ e em $B$, surtos de ondas "sharp" de elevado potencial, com ondas lentas pós-descarga, projetando-se em área correspondente a $C_{3}$ e áreas vizinhas. Paciente portador de crises sòmente há 5 meses e que já evidenciava êsse foco ativo em EEG feito em fevereiro de 1954.

O aparecimento dêsse foco ativo foi ulterior ao processo de "cura" do abscesso em 8 pacientes, nos quais o EEG feito antes da intervenção não evidenciava qualquer sinal do foco epileptógeno ativo, tendo o aparecimento dêsse foco se processado precocemente em 2 pacientes (dentro de 30 a 60 dias nos casos 5 e 8 ), e tardiamente nos demais. Cite-se, por exemplo, o caso 16, já anteriormente comentado, com EEG normal até 5 meses depois da operação, que apresentou crises convulsivas 25 meses depois, quando, entāo, o EEG mostrou também foco epileptógeno.

Dois pacientes apresentavam sinais de foco epileptógeno no EEG quando da primeira consulta, isto é, em periodo pré-operatório (casos 7 e 9), momento em que apresentaram também síndrome convulsiva. Não é demais relembrar que o foco do caso 9 reapareceu sỏmente 19 meses após operação, sendo normais quatro exames eletrencefalográficos feitos nesse intervalo; as manifestaçōes clínicas convulsivas, raras, estiveram sempre presentes. Já em relação ao caso 7 não podemos fazer essa correlação porque a paciente só voltou para reexame 37 e 42 meses depois da operação, quando ainda manifestava o mesmo foco ativo e a sindrome convulsiva.

Não nos é possível estabelecer certamente qual a época de aparecimento do foco ativo, pois que não tivemos ocasião de examinar todos os pacientes em periodo intermediário; em todos êles, entretanto, uma vez verificado, o foco ativo se manteve nos exames subseqüentes. 
Clìnicamente 8 pacientes apresentaram manifestaçōes convulsivas. $E$ de se salientar o caso 2, no qual estas manifestações foram precedidas, de 5 meses, pelo aparecimento de foco ativo no EEG. O caso 11 apresentou convulsões sem foco nitido no EEG; entretanto, como o exame foi feito só 3 meses após operação, é possivel que ulteriormente tenha sobrevindo o foco.

Merece especial menção o fato que dos 10 pacientes com foco epileptógeno sòmente um apresentava distúrbios mentais e do comportamento, mostrando que as seqüelas do abscesso cerebral dependem de processo lesional restrito no cérebro, do qual o foco epileptógeno ativo é uma manifestação.

Estas observações permitem considerar o exame eletrencefalográfico em série como um método semiológico auxiliar de grande interêsse na seqüência dos casos de abscesso cerebral, quer porque êle mostra, inicialmente, o desaparecimento ou não das ondas delta tão características dêsse processo, indicando assim a evolução favorável ou não do processo mórbido agudo, quer porque pode apresentar alterações que revelam sòmente seqüela do processo, e, portanto, indicar sua evolução para a cura. A ênfase nesses resultados deve ser feita, entretanto, para os casos em que se evidencia aparecimento de sinais da formação do foco epileptógeno ativo; êstes elementos têm relevante significação não só no prognóstico final do caso (possibilidade, aliás, muito freqüente, da instalação de síndrome convulsiva pós-abscesso), como também na indicação do estabelecimento de um esquema de tratamento anticonvulsivante com finalidade profilática.

Tais resultados estão em consonância com os pontos de vista expendidos por Bagchi ${ }^{1}$ e por Schwabb ${ }^{4}$ no que diz respeito, particularmente, à presença de foco epileptógeno, e com os de Farbrot ${ }^{6}$, de Hoen e col.; em relação ao significado mau da persistência de ondas delta muito lentas e de elevado potencial.

\section{CONCLUSOES}

1) O EEG apresentou alterações definidas em $100 \%$ dos casos de abscesso cerebral examinados. A presença de ondas delta, de elevado potencial e freqüência 0,5 a $1,5 \mathrm{c} / \mathrm{s}$, focais, evidente em 19 dos 20 pacientes examinados, e a de depressão focal do ritmo de base evidente em 11 dêsses pacientes, foram os elementos eletrencefalográficos predominantes.

2) O EEG permitiu diagnóstico topográfico certo em 16 dos 20 pacientes. Em 2 sòmente permitiu diagnóstico do hemisfério afetado e em outros 2 forneceu elementos de diagnóstico, mas permitiu êrro quanto ao hemisfério; tal êrro foi devido à predominância de ondas delta em áreas homólogas de hemisfério oposto; em ambos êstes dois últimos casos havia depressão do ritmo de base como sinal de localização do abscesso.

3) O EEG constitui elemento de real valor para o diagnóstico de abscesso cerebral, particularmente quando interpretado em função da clínica. Ele permite também o diagnóstico topográfico ou, pelo menos, o diagnóstico de hemisfério lesado, permitindo orientar a arteriografia. 
4) O EEG feito 30 dias após a intervenção cirúrgica mostrou persistência fugaz de ondas delta sòmente em 3 de 17 casos; todos apresentavam sinais clínicos de sofrimeñto do parênquima nervoso. Nos demais casos, as alteraçōes eletrencefalográficas foram frustras (depressões do ritmo de base ou sinais de foco epileptógeno), em correlação com a cura clínica do processo purulento.

5) O EEG pode ser de grande utilidade como meio auxiliar para o diagnóstico de "cura" do abscesso cerebral, e, conseqüentemente, para o prognóstico da afecção.

6) Não houve, como é óbvio, correlação entre seqüelas neurológicas (hemiplegias, afasia, etc.) e alterações no EEG.

7) Em 10 entre 17 casos houve aparecimento de foco convulsiógeno ativo, sendo que em 8 dêsses pacientes manifestaram-se convulsões clínicas. Em um outro paciente, precocemente, apresentaram-se convulsões sem foco epileptógeno correspondente.

8) Em 2 pacientes, após a intervenção cirúrgica, houve precedência de aparecimento do foco no EEG em relação à eclosão das crises convulsivas.

9) Focos epileptógenos, assim como crises convulsivas, apareceram com intervalos de 1 até 19 e mesmo 25 meses após a operação.

10) Em sòmente 2 pacientes havia foco ativo no EEG pré-operatório, enquanto que 6 pacientes apresentaram crises clínicas na fase aguda da moléstia, antes da intervenção terapêutica.

11) Tais elementos permitem supor que a natureza do processo anátomo-patológico, inflamatória aguda na fase inicial e conjuntivo-cicatricial na fase final da moléstia, explique essa diferença de aparecimento dos focos epileptógenos ativos em tais pacientes.

12) Assim sendo, o EEG, pela evidenciação do foco epileptógeno ativo, permite anunciar a fase crônica do processo, como permite também ajuizar do prognóstico do caso, pela eventualidade do aparecimento de síndrome convulsiva pós-abscesso.

\section{RESUMO}

Os autores, que vêm fazendo exames eletrencefalográficos sistematizada. mente em casos de abscessos cerebrais desde 1951, relatam sua experiência, ressaltando os elementos que o EEG proporciona para o diagnóstico e prognóstico dêsses processos.

O material que apresentam é de 22 casos $(20$ com EEG pré-operatório, 17 dos quais com seguimento eletrencefalográfico pós-operatório, e 2 nos quais só foi feito EEG pós-operatório) com diagnóstico confirmado pela arteriografia e pela intervenção cirúrgica. Todos foram submetidos a trata- 
mento cirúrgico e antibiótico, sendo o seguimento clínico-eletrencefalográfico a partir do $30^{\prime}$ dia após a intervenção cirúrgica.

No grupo dos pacientes com EEG pré-operatório foram encontradas alterações difusas do traçado em 20 casos (100\%) e alterações focais consistentes em ondas delta 0,5 a $3 \mathrm{c} / \mathrm{s}$, potencial de 400 a $500 \mathrm{mV}$ (19 casos), depressão focal do ritmo de base (11 casos), foco epileptógeno ( 2 casos). As ondas delta bastante lentas e a depressão focal do ritmo de base constituem elemento de valor para o diagnóstico, particularmente quando interpretados em consonância com a clínica.

No grupo de pacientes seguidos com exames clínicos e eletrencefalográficos sistemáticos, por um periodo que variou de 1 a 60 meses, foram encontrados sinais de foco convulsiógeno ativo em 10 dos 17 pacientes observados. $\mathrm{Na}$ opinião dos autores êste índice anormalmente elevado está em consonância com a freqüência de epilepsia pós-abscesso cerebral. O tempo que decorreu entre a operação e o aparecimento do foco ativo variou de 1 até 25 meses. Dêsses 10 pacientes com foco ativo e com epilepsia clìnicamente comprovada, somente 2 tinham foco anteriormente ao processo de "cura" do abscesso. Os autores discutem êsse problema e pensam ser os processos de cicatrização — processos crônicos —os responsáveis por tais manifestações clínico-eletrencefalográficas.

Ainda neste grupo chamam atenção para o fato de que em sòmente 4 pacientes o EEG continuou a se manter normal durante todo periodo de observação, sendo que 2 outros tiveram EEG normal por 5 e 15 meses, respectivamente, e, mais tarde apresentaram foco ativo. Ao lado dêstes focos epileptógenos, em 3 pacientes havia também sinais de sofrimento do parênquima nervoso (ondas delta) 1 a 3 meses depois da intervenção cirúrgica (casos com convulsões reiteradas ou ainda com sinais do abscesso em evolução). Em 6 casos havia certa depressão focal pós-operatória no EEG; em 4 havia alterações frustras do ritmo de base, alterações estas de tipo cicatricial e sem correlação clínica correspondente.

Concluem os autores que o EEG constitui excelente método auxiliar no diagnóstico de abscessos cerebrais e, principalmente, elemento muito útil no prognóstico dos casos tratados, quer evidenciando desaparecimento dos sinais agudos de comprometimento cerebral, quer fornecendo precocemente sinais da formação de foco convulsiógeno ativo, possibilitando a instituição precoce de terapêutica anticonvulsiva.

\section{SUMMARY}

Electroencephalography in the diagnosis and prognosis of cerebral abscess.

The authors have made electroencephalographic studies in cases of cerebral abscess since 1951; these records were always obtained before any neurosurgical treatment and were repeated several times after the surgical approach. The authors call the attention to the important data that the 
EEG can offer to the diagnosis of cerebral abscess and to the prognosis in patients who were operated on.

Twenty-two patients (20 had EEG previously to the surgical treatment, 17 with repeated EEG after the operation and 2 had EEG only after the operation) were clinically and electroencephalographically studied, the diagnosis being confirmed by arteriograms and by the surgical treatment. All patients were operated on and received antibiotics. In the present paper the EEG changes found during the first month following the surgical treatment were not included.

In the group of patients with EEG obtained before the surgical treatment, the authors found difuse changes in the record of the 20 patients (100 per cent), and focal changes consisting mainly by delta waves of $0.5-3 \mathrm{c} / \mathrm{s}$, potential of $400-500 \mathrm{mV}$ (19 cases) focal depression of the basic rhythm (11 cases); epileptogenic focus was found only in 2 cases. The very slow delta waves and focal depression of the basic rhythm represent very important data for the diagnosis, particularly when studied in relation to the clinic data.

In the group of patients who had clinical and EEG examinations after the operation, being the EEG records repeated during a period of time from one to 60 months, the authors found signs of active convulsive focus in 10 out of 17 patients. In the opinion of the authors this incidence is very high and it is in accordance with the high frequency of epilepsy following cerebral abscess. The lenght of time between the operation and the onset of the focal activity varied from one to 25 months. Out of the 10 patients with focal activity and with clinical epilepsy, only 2 patients had presented focal activity before to the "healing" of the abscess. The authors discuss this problem and believe that the healing, which is a chronic process, is the responsible for the onset of these clinically and electroencephalographically manifestations.

In the same group only 4 patients had normal EEG during all the follow-up; 2 patients had normal EEG during 5 and 15 months, but developed focal activity later on. Other 3 patients had signs of suffering of the nervous tissue (delta waves) from one to 3 months after the operation (patients with convulsive seizures or still with signs of abscess in evolution). In 6 cases there was slight changes of the basic rhythm, which were due to the healing and with no clinical correlation.

The authors conclude that the EEG is a very important auxiliary method for the diagnosis of cerebral abscess and for the prognosis of those cases surgically treated, since it shows disappearance of acute signs of cerebral involvement, or early formation of active convulsive focus, permitting the begining of the anticonvulsive therapy.

\section{BIBLIOGRAFIA}

1. BACCHI, B. K. - Comunicação pessoal. 2. COBB, W. A. - Electrencephalography. Mac Donald \& Co., London, 1950, págs. 273-301. 3. COURJON, J.; CORRIOL, J. - L'EEG dans les abscèss du cerveau. EEG Clin. a. Neurophysiol., 1:375, 1949. 4. 
COURVILLE, C. - The effect of certain lesions of the brain on electroencephalographic wave patterns. Bull. Los Angeles Neurol. Soc., 14:110-148 (setembro) 1949. 5. COHN. R. - Clinical Electroencephalography. Mc Graw-Hill Book Co. Inc., New York, 1949. 6. FARBROT, O. - Remarks on electroencephalography in cerebral abscess. Acta Psychiat. et Neurol., 25:167-178, 1950. 7. HOEN, TH.; ANDERSON, R.: CLARE, F. - Metastatic brain abscess originating in the lungs treated with massive doses of penicillin. Naval Med. Bull., 48:778-787 (setembro-outubro) 1948. 8. PENNYBACKER, J. - Abscess of the Brain. In Modern Trends in Neurology. A. Feiling. Butterworth \& Co. Ltd., 1951, págs. 255-290. 9. PINE, I.; ATOYNATAN, T. H.; MARGOLIS, G. - The EEG findings in eighteen patients with brain abscess: case reports and review of the literature. EEG. Clin. a. Neurophysiol., 4:165-179, 1952. 10. PUECH. M. P.; LERIQUE-KOECHLIN, M. - Lélectroencéphalographie dans les abscèss du cerveau. Rev. Neurol., 76:303-305, 1944. 11. SCHWABB, R. S.; CARTER, R. - Electroencephalography in relation to otology. Laryngoscope, 52:757 (outubro) 1942.12. SCHWABB, R. S. - Brain Abscess. In Electroencephalography in Clinical Practice. W. B. Saunders Co., Philadelphia, 1951, pág. 120. 13. WALTER, W. G. - Cit. por Pine, Atoynatan e Margolis". 14. WILLIAMS, D.; REYNELL, J. - Abnormal supression of cortical frequencies. Brain, 68:123-161, 1954. 15. ZIEGLER, D.; HOEFER, D. - Electroencephalographic and clinical findings in 28 verifled cases of brain abscess. EEG. Clin. a. Neurophysiol., 4:41-44, 1952.

Clínica Neurológica - Escola Paulista de Medicina -- Caixa Postal 5496 São Paulo, Brasil. 